\title{
Oryeongsan inhibits LPS-induced production of inflammatory mediators via blockade of the NF-kappaB, MAPK pathways and leads to $\mathrm{HO}-1$ induction in macrophage cells
}

You-Chang Oh, Yun Hee Jeong, Jeong-Ho Ha, Won-Kyung Cho* and Jin Yeul Ma*

\begin{abstract}
Background: Oryeongsan (OR) is an herbal medication used in east-Asian traditional medicine to treat dysuresia, such as urinary frequency, hematuria, and dysuria due to renal disease and chronic nephritis. Recent studies showed that protective effect against acute gastric mucosal injury and an inhibitory effect on the renin-angiotensinaldosterone pathway of OR. However, its effect on inflammation still remains unknown. In this study, to provide insight into the biological effects of OR, we investigated their effects on lipopolysaccharide (LPS)-mediated inflammation in the RAW 264.7 macrophage cells.

Methods: We investigated the pharmacological and biological effects of OR on the production of pro-inflammatory cytokines, inflammatory mediators, and related products through Enzyme-linked immunosorbent assay (ELISA), reverse transcription-polymerase chain reaction (RT-PCR) and Western blot analysis. Also, we examined the activation and suppression of nuclear factor (NF)-kappaB and mitogen-activated protein kinases (MAPKs) pathways in LPS-stimulated macrophages via Western blot analysis in order to explore inhibitory mechanism of OR.

Results: OR had anti-inflammatory effects by inhibiting the production of nitric oxide (NO), tumor necrosis factor (TNF)-alpha, interleukin (IL)-6, and IL-1 beta. In addition, it strongly suppressed cyclooxygenase (COX)-2 and inducible nitric oxide synthase (iNOS), NO synthesizing enzymes. It also induced heme oxygenase (HO)-1 expression and inhibited NF-kappaB signaling pathway activation and phosphorylation of MAPKs.

Conclusions: We further demonstrate the anti-inflammatory effects and inhibitory mechanism of OR in LPS-stimulated macrophages for the first time. OR contains strong anti-inflammatory activity and affects various mechanism pathways including NF-kappaB, MAPKs and HO-1. Our results suggest that OR has potential value to be developed as an inflammatory therapeutic agent from a natural substance.
\end{abstract}

Keywords: Oryeongsan, Inducible nitric oxide synthase, Heme oxygenase-1, Nuclear factor-kappaB, Mitogen-activated protein kinase

\footnotetext{
*Correspondence: jyma@kiom.re.kr; wkcho@kiom.re.kr

Korean Medicine (KM)-Based Herbal Drug Development Group, Korea

Institute of Oriental Medicine, Yuseong, Daejeon, Republic of Korea
} 


\section{Background}

OR is a traditional ancient herbal medication in East Asia. It is a prescription described in the Sanghanron, an ancient Chinese medical book. OR is composed of five medicinal herbs including Alisma Rhizome, Atractylodes Rhizome White, Chuling, Poria and Cinnamon Bark. OR is currently prescribed for the treatment of edema, dizziness, vomiting and symptoms associated with renal disease. A previous study demonstrated that OR protects against ethanol-induced acute gastric mucosal injury [1]. Another study revealed that OR has an inhibitory effect on the renin-angiotensin-aldosterone system in rats [2]. Additionally, recent studies have shown that amelioration of streptozotocin diabetes-induced renal damage by OR [3]. It has also been reported that OR exert protective effect on adriamycin-induced nephrotic syndrome in rats [4]. However, the effect of OR on inflammation remains unknown.

Inflammation is a normal physiological immune response to protect body from infection or tissue injury and results in activation of various immune cells such as macrophages, neutrophils, and lymphocytes. In normal state, inflammatory mediators, such as NO and inflammatory cytokines, generated from macrophage cells take an essential role in host survival and tissue repair [5]. However, these inflammatory mediators are overexpressed by certain stimuli and could cause autoimmune and inflammatory diseases [6-8].

Macrophages play an important role in the regulation of inflammation and immune responses $[6,9]$. Specific stimuli such as LPS which is endotoxin from gram-negative bacteria, give rise to activation of macrophages. Activated macrophages secrete inflammatory mediators such as $\mathrm{NO}$ and prostaglandin (PG) $\mathrm{E}_{2}$ and produce inflammatory cytokines such as TNF- $\alpha$ and IL-6 [5,10]. These inflammatory mediators and cytokines are essential for host survival after infection, and are necessary for the recovery of tissue damage [5]. $\mathrm{NO}$ and $\mathrm{PGE}_{2}$ are synthesized by iNOS and COX-2, respectively, and iNOS expression is closely related to the induction of $\mathrm{HO}-1$.

$\mathrm{HO}-1$ is a stress-inducible protein that catalyzes the oxidative degradation of heme. Two other isoforms exist: HO-2 and HO-3 [11]. HO-1 expression is enhanced not only by free heme, but also by various pro-inflammatory stimulants such as NO, LPS, cytokines, heavy metals, and other oxidants [12,13]. Biliverdin is rapidly transformed into bilirubin, which decreases NO production and iNOS expression in murine macrophages stimulated with LPS $[14,15]$. Carbon monoxide, another product of heme degradation by $\mathrm{HO}$, inhibits $\mathrm{NO}$ secretion and reduces inflammation. Thus, enhanced HO-1 production may result in the reduction of iNOS expression and decrease the amount of free radicals [16].

Among the cytokines, TNF- $\alpha$, IL- 6 and IL- $1 \beta$ are important factors involved in the progression of many inflammatory diseases. These cytokines can be regulated by activation of the transcription factor NF- $\kappa B$. NF- $\kappa B$ is composed of homo or heterodimeric combinations of NF- $\mathrm{B}$ /Rel proteins, including Rel (cRel), RelA (p65), RelB, NF-kB1 (p50) and NF-kB2 (p52) [17]. The main inducible form is consisting of the p65 and p50 subunit. NF- $\kappa B$ plays an important role in the expression of inflammatory genes, and is involved in the pathogenesis of rheumatism and other chronic inflammatory diseases [18]. In unstimulated state, NF- $\mathrm{kB}$ is present in the cytoplasm attached to the suppressor protein inhibitor of NF- $\kappa B$ alpha $(\mathrm{I} \kappa \mathrm{B} \alpha)$, but specific stimulants such as LPS give rise to free $N F-\kappa B$ through degradation and phosphorylation of $I \kappa B \alpha$ [19]. Activated NF- $\kappa B$ is translocated from the cytoplasm to the nucleus, then binds to the promoter and induces the expression of various inflammatory genes including iNOS, COX-2, inflammatory cytokines, and chemokines [20,21]. Previous studies showed that nuclear translocation of NF- $\mathrm{kB}$ promotes the transcription of iNOS, COX-2 and inflammatory cytokines including TNF- $\alpha$ and IL-6 [22]. Most anti-inflammatory agents reduce the expression of inflammatory factors via inhibition of NF- $\mathrm{kB}$ activity [23].

The MAPK signaling pathway plays an important role in relaying inflammatory information from the extracellular space to the cytoplasm and nucleus [24]. There are at least three known pathways of MAPK, such as extracellular signal-regulated kinase (ERK), p38 and c-Jun $\mathrm{NH}_{2}$-terminal kinase (JNK) MAPK. Activated ERK can phosphorylate various transcription factors; p38 and JNK constitute a part of the stress response pathway activated by various stimulants induced by specific factors [25]. MAPK is activated by phosphorylation, and subsequently induces the activation of NF- $\mathrm{kB}$ pathway and expression of iNOS gene. A previous study demonstrated that specific MAPK inhibitors can reduce iNOS gene expression [26]. In the present study, we evaluated the inhibitory effect of OR on inflammation induced by LPS in RAW 264.7 macrophages. Furthermore, we investigated whether OR-induced modulation of NF- $\mathrm{kB}$ and MAPK signaling pathways and their influence on $\mathrm{HO}-1$ induction were responsible for the anti-inflammatory effects of OR.

\section{Methods}

\section{Materials and reagents}

Roswell Park Memorial Institute (RPMI) 1640 medium, fetal bovine serum (FBS), and antibiotics were purchased from Lonza (Basel, Switzerland). LPS and bovine serum albumin (BSA) were obtained from Sigma (St. Louis, MO, USA). A cell-counting kit (CCK) was purchased from Dojindo Molecular Technologies, Inc. (Kumamoto, Japan). Various primary and secondary antibodies for Western blot analysis were purchased from Cell Signaling Technology, 
Inc. (Boston, MA, USA). ELISA antibody sets for cytokine detection were obtained from eBioscience (San Diego, CA, USA). RNA extraction and DNA synthesizing kits were purchased from iNtRON (Sungnam, Korea) and Bioneer (Daejeon, Korea), respectively. Oligonucleotide primers were synthesized by Bioneer (Daejeon, Korea). The standard compounds cinnamic acid and cinnamaldehyde were purchased from Sigma (St. Louis, MO, USA), and atractylenolid III was purchased from Chem Faces (Wuhan, China). Marker compound purity, as determined by high-performance liquid chromatography (HPLC), was higher than 98\%. HPLC grade acetonitrile and trifluoroacetic acid (TFA) were purchased from J. T. Baker Inc. (Philipsburg, NJ, USA). Distilled water (DW) was filtered through a $0.45-\mu \mathrm{m}$ membrane filter from ADVANTEC (Tokyo, Japan) before analysis.

\section{Preparation of herbal decoction OR}

OR is composed of five medicinal herbs listed in Table 1. All herbs were purchased from Yeongcheon Herbal Market (Yeongcheon, Korea). All voucher specimens were deposited in an herbal tank, placed in $15,000 \mathrm{~mL}$ of DW and then extracted by heating for $3 \mathrm{~h}$ at $115^{\circ} \mathrm{C}$ and under high pressure (Gyeongseo Extractor Cosmos-600, Inchon, Korea). After extraction, the solution was filtered using standard testing sieves $(150 \mu \mathrm{m})$ (Retsch, Haan, Germany), freezedried and kept in desiccators at $4{ }^{\circ} \mathrm{C}$ before use. The acquisition was $347 \mathrm{~g}$ and the yield was $23.2 \%$. The freeze-dried extract powder was then dissolved in DW, centrifuged at $14000 \mathrm{rpm}$ for $10 \mathrm{~min}$ and supernatant was filtered (pore size, $0.2 \mu \mathrm{m}$ ) and kept at $4^{\circ} \mathrm{C}$ prior to use.

\section{Cell culture and drug treatment}

RAW 264.7 cells were obtained from the Korea Cell Line Bank (Seoul, Korea) and grown in complete RPMI 1640 medium. The cells were incubated in a humidified $5 \% \mathrm{CO}_{2}$ atmosphere at $37^{\circ} \mathrm{C}$. To stimulate the cells, the medium was exchanged with fresh RPMI 1640 medium, and LPS (200 ng/mL) was added in the presence or absence of OR $(10,100,500$, or $1000 \mu \mathrm{g} / \mathrm{mL})$ for the indicated periods.

\section{Cell viability assay}

Cytotoxicity was analyzed using a CCK. OR was added to the cells and incubated for $24 \mathrm{~h}$ at $37^{\circ} \mathrm{C}$ with $5 \% \mathrm{CO}_{2}$. CCK solutions were added to each well and the cells

Table 1 Herbal components and amount of OR decoction

\begin{tabular}{cc}
\hline Herbs & Amount of herbs (g) \\
\hline Alisma Rhizome & 500 \\
Atractylodes Rhizome White & 300 \\
Chuling & 300 \\
Poria & 300 \\
Cinnamon Bark & 100 \\
\hline
\end{tabular}

were incubated for another $1 \mathrm{~h}$. Then the optical density was read at $450 \mathrm{~nm}$ using an ELISA reader (Infinite M200, Tecan, Männedorf, Switzerland).

\section{Measurement of NO production}

NO production was analyzed by measuring nitrite in the supernatants of macrophages incubated with or without OR. The cells were pretreated with OR and stimulated with LPS for $24 \mathrm{~h}$. Griess reagent (1\% sulfanilamide, $0.1 \%$ naphthylethylenediamine dihydrochloride, and $2.5 \%$ phosphoric acid) was added to the cultured supernatant and incubated at room temperature (RT) for $5 \mathrm{~min}$ [27]. The absorbance was read at $570 \mathrm{~nm}$.

\section{Determination of cytokine production}

The secretion of inflammatory cytokines TNF- $\alpha$, IL- 6 and IL-1 $\beta$ was analyzed using an eBioscience mouse ELISA antibody set (San Diego, CA, USA). The inhibitory effect of OR was determined by an ELISA reader at $450 \mathrm{~nm}$ absorbance.

\section{Western blot analysis}

Expression of various proteins was evaluated by Western blot analysis according to standard procedures. The cells were pretreated with OR and stimulated with LPS for the indicated periods at $37^{\circ} \mathrm{C}$. After incubation, the cells were harvested and resuspended in radio immunoprecipitation assay (RIPA) lysis buffer (Millipore, Bedford, MA, USA) with protease and phosphatase inhibitor cocktail (Roche, Basel, Switzerland). After cell debris was discarded following centrifugation, protein concentration was determined using Bradford's reagent and equal amounts of protein were subjected to sodium dodecyl sulfate-polyacrylamide gel electrophoresis (SDS-PAGE). After transferring the proteins onto a nitrocellulose membrane (Millipore, Bedford, MA, USA), the membrane was blocked with $3 \%$ BSA in Trisbuffered saline with $0.1 \%$ Tween 20 (TBS-T). Then the membrane was incubated with each primary antibody at $4^{\circ} \mathrm{C}$ overnight and subsequently incubated with HRPconjugated secondary antibodies. Specific proteins were detected using SuperSignal West Femto Chemiluminescent Substrate (Thermo Scientific, Rockford, IL, USA).

\section{Preparation of cytosolic and nuclear extracts for NF-KB detection}

Cytosolic and nuclear fractions were isolated using NE-PER Nuclear and Cytoplasmic Extraction Reagents (Thermo Scientific, Rockford, IL, USA) according to the procedure described by the manufacturer. The fractions were stored at $-80^{\circ} \mathrm{C}$ before use.

\section{RNA extraction and RT-PCR}

Total RNA was isolated using an easy-BLUE ${ }^{\mathrm{TM}}$ RNA extraction kit (iNtRON, Daejeon, Korea) according to the 
Table 2 Primers used for RT-PCR analysis

\begin{tabular}{|c|c|c|}
\hline $\begin{array}{l}\text { Target } \\
\text { gene }\end{array}$ & Primer sequence & $\begin{array}{l}\text { Annealing } \\
\text { temp }\end{array}$ \\
\hline \multirow[t]{2}{*}{ TNF-a } & F: 5'-AGCACAGAAAGCATGATCCG-3' & $55^{\circ} \mathrm{C}$ \\
\hline & R: 5'-GTTTGCTACGACGTGGGCTA-3' & \\
\hline \multirow[t]{2}{*}{ IL-6 } & F: 5'-CATGTTCTCTGGGAAATCGTGG-3' & $58^{\circ} \mathrm{C}$ \\
\hline & R: 5'-AACGCACTAGGTTTGCCGAGTA-3' & \\
\hline \multirow[t]{2}{*}{ IL-1 $\beta$} & F: 5'-TGCAGAGTTCCCCAACTGGTACATC-3' & $64^{\circ} \mathrm{C}$ \\
\hline & R: 5'-GTGCTGCCTAATGTCCCCTTGAATC-3' & \\
\hline \multirow[t]{2}{*}{$\operatorname{cox}-2$} & F: 5'-CACTCAGTTTGTTGAGTCATTC-3' & $45^{\circ} \mathrm{C}$ \\
\hline & R: 5'-GATTAGTACTGTAGGGTTAATG-3' & \\
\hline \multirow[t]{2}{*}{ iNOS } & F: 5'-AGCCCAACAATACAAATGACCCTA-3' & $56^{\circ} \mathrm{C}$ \\
\hline & R: 5'-TTCCTGTTGTTTCTATTTCCTTTGT-3' & \\
\hline \multirow[t]{2}{*}{ HO-1 } & F: 5'-TGAAGGAGGCCACCAAGGAGG-3' & $62^{\circ} \mathrm{C}$ \\
\hline & R: 5'-AGAGGTCACCCAGGTAGCGGG-3' & \\
\hline \multirow[t]{2}{*}{$\beta$-actin } & F: 5'-ATGAAGATCCTGACCGAGCGT-3' & $58^{\circ} \mathrm{C}$ \\
\hline & R: 5'-AACGCAGCTCAGTAACAGTCCG-3' & \\
\hline
\end{tabular}

$F$, forward; $R$, reverse.

procedure described by the manufacturer. The total RNA was transformed into cDNA using AccuPower ${ }^{\circ}$ CycleScript RT PreMix (Bioneer, Daejeon, Korea). Specific primers amplified by PCR are described in Table 2. The following PCR conditions were applied for TNF- $\alpha$, IL-6, IL- $1 \beta$, COX-2, iNOS, HO- 1 , and $\beta$-actin: 35 cycles of denaturation at $94^{\circ} \mathrm{C}$ for $30 \mathrm{~s}$, annealing at the temperature indicated in Table 2 for 30 seconds, and extension at $72^{\circ} \mathrm{C}$ for 30 seconds [27-31].

\section{Preparation of standard solutions and samples}

Standard stock solutions of atractylenolid III, cinnamic acid and cinnamaldehyde were prepared by dissolving $0.2 \mathrm{mg}$ each standard in $1 \mathrm{~mL} 60 \%$ methanol to yield a final concentration of $200 \mu \mathrm{g} / \mathrm{mL}$. To prepare analytical samples, $10 \mathrm{mg}$ OR extract in $1 \mathrm{~mL}$ DW was extracted by ultra-sonication and filtered through a $0.2-\mu \mathrm{m}$ syringe membrane filter from Whatman Ltd. (Maidstone, UK) before injection into the HPLC system for analysis. All standard stock and sample solutions were stored at $-4^{\circ} \mathrm{C}$ in a refrigerator before analysis.

\section{Chromatographic conditions}

The HPLC-DAD system (Hitachi, Tokyo, Japan) consisted of a pump (L-2130), autosampler (L-2200), column oven (L-2300) and UV/VIS diode array detector (L-2455). The output signal of the detector was recorded using EZChrom Elite software for Hitachi. For sample analysis, an OptimaPak $\mathrm{C}_{18}$ column $(4.6 \times 250 \mathrm{~mm}, 5 \mu \mathrm{m}$; RS Tech Co., Daejeon, Korea) was used, and the column oven temperature was kept at $35^{\circ} \mathrm{C}$. The injection volume was $20 \mu \mathrm{L}$, and the flow rate of the mobile phase was $1.0 \mathrm{~mL} /$ min. The wavelength of the UV detector was set at $220 \mathrm{~nm}$. The mobile phase was water containing $0.1 \%$ TFA and acetonitrile, with gradient elution at a flow rate of $1.0 \mathrm{~mL} /$ min (Table 3).

\section{Statistical analysis}

The results are expressed as mean \pm standard error (SE) for all experiments. Statistical significance was determined by Student's t-tests after comparing each treated group to the negative control. Each experiment was repeated at least three times to yield comparable results. Values of $\mathrm{P}<0.01$ and $\mathrm{P}<0.001$ were considered statistically significant.

\section{Results}

Effects of OR on cell viability and NO production

We first examined OR cytotoxicity at concentrations of $10-1000 \mu \mathrm{g} / \mathrm{mL}$ in macrophages. As shown in Figure 1A, OR was not cytotoxic up to $1000 \mu \mathrm{g} / \mathrm{mL}$, indicating that

Table 3 HPLC conditions used for the analysis of OR

\begin{tabular}{lccc}
\hline Item & \multicolumn{1}{c}{ Condition } \\
\cline { 2 - 4 } Mobile phase & Time (min) & Water (containing 0.1\% TFA) & Acetonitrile \\
\hline & 5 & 90 & 10 \\
& 40 & 90 & 10 \\
& 40 & 0 & 10 \\
& 60 & 0 & 100 \\
Flow rate & $1.0 \mathrm{~mL} / \mathrm{min}$ & & \\
Inject volume & $20 \mu \mathrm{L}$ & & \\
Column & OptimaPak $\mathrm{C}_{18}(4.6 \times 250 \mathrm{~mm}, 5 \mu \mathrm{mm}, \mathrm{RS}$ tech Co., Daejeon, Korea) \\
Column temperature & $40^{\circ} \mathrm{C}$ & & \\
UV wavelength & $220 \mathrm{~nm}$ &
\end{tabular}

The English in this document has been checked by at least two professional editors, both native speakers of English. For a certificate, please see: http://www.textcheck.com/certificate/7WNmoy. 

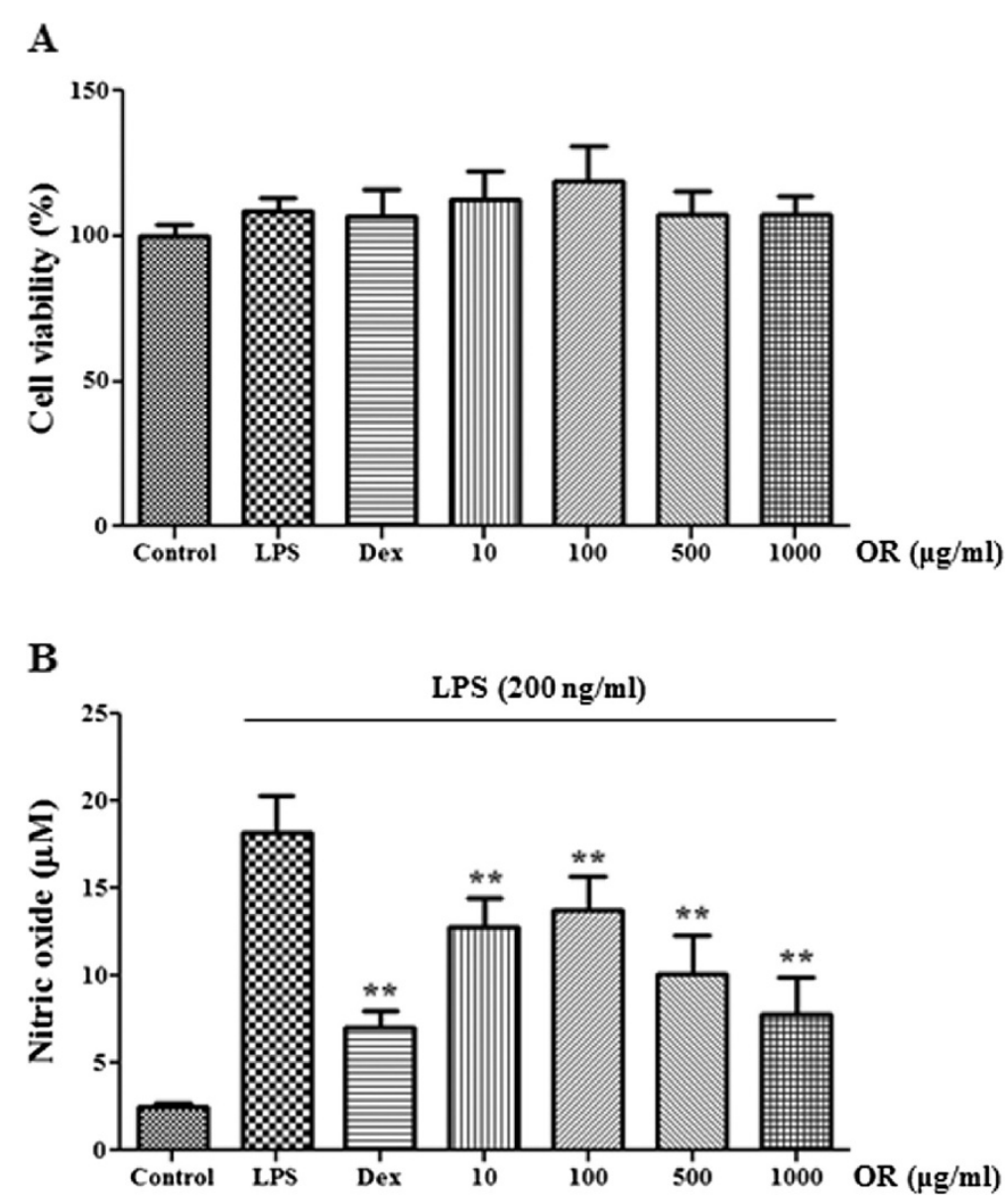

Figure 1 Effect of OR on (A) cell viability and (B) NO production induced by LPS stimulation. RAW 264.7 cells were pretreated with OR for 30 min before $24 \mathrm{~h}$ incubation with LPS. (A) The cytotoxicity was determined using CCK. (B) The culture supernatant was analyzed for nitrite production. As a control, the cells were incubated with vehicle alone. Data represent mean \pm SE values of duplicate determinations from three independent experiments. ${ }^{*} p<0.01$ and ${ }^{* *} p<0.001$ were calculated from comparisons with the LPS-stimulation value.

OR is not toxic to macrophages. Because NO inhibition can relieve inflammation, we examined the inhibitory effect of OR on NO generation in RAW 264.7 cells upon LPS stimulation. Dexamethasone, a well-known anti-inflammatory drug, was used as a positive control. As presented in Figure 1B, OR concentration-dependently suppressed NO secretion with statistical significance. In particular, OR $(1000 \mu \mathrm{g} / \mathrm{mL})$ inhibited NO secretion to a similar extent as observed with the positive control.

\section{Inhibitory effect of OR on LPS-induced TNF- $\alpha$, IL- 6 and IL-1 $\beta$ production}

We examined the inhibitory effect of OR on the expression of TNF- $\alpha$, IL- 6 and IL- $1 \beta$ cytokines, other inflammatory mediators. Cytokine expression was analyzed using ELISA and RT-PCR analysis. TNF- $\alpha$ cytokine and mRNA were inhibited by $\mathrm{OR}$ treatment in a concentrationdependent fashion (Figure 2A and D). Consistent with the TNF- $\alpha$ result, OR also inhibited IL-6 cytokine production concentration-dependently (Figure 2B). However, the inhibitory effect of OR on IL-6 mRNA expression was negligible, with the exception of the effect of the $1000 \mu \mathrm{g} / \mathrm{mL}$ concentration (Figure 2D). By contrast, OR slightly inhibited IL- $1 \beta$ cytokine production and strongly repressed IL-1 $\beta$ mRNA expression (Figure $2 \mathrm{C}$ and $\mathrm{D}$ ).

\section{Inhibitory effect of OR on LPS-induced COX-2 and iNOS} expression, and OR effect on HO-1 induction

COX-2 and iNOS are the synthesizing enzymes of $\mathrm{PGE}_{2}$ and $\mathrm{NO}$, respectively. Therefore, COX-2 and iNOS expression were next investigated using Western blot and RT-PCR. As presented in Figure 3A and B, OR suppressed both protein and mRNA expression of COX-2 and iNOS. In particular, expression of COX-2 and iNOS protein was significantly inhibited in a concentration-dependent manner. We also examined HO-1 induction in OR-treated macrophages, which is known to contribute to the inflammatory response. Western blot and RT-PCR analysis 


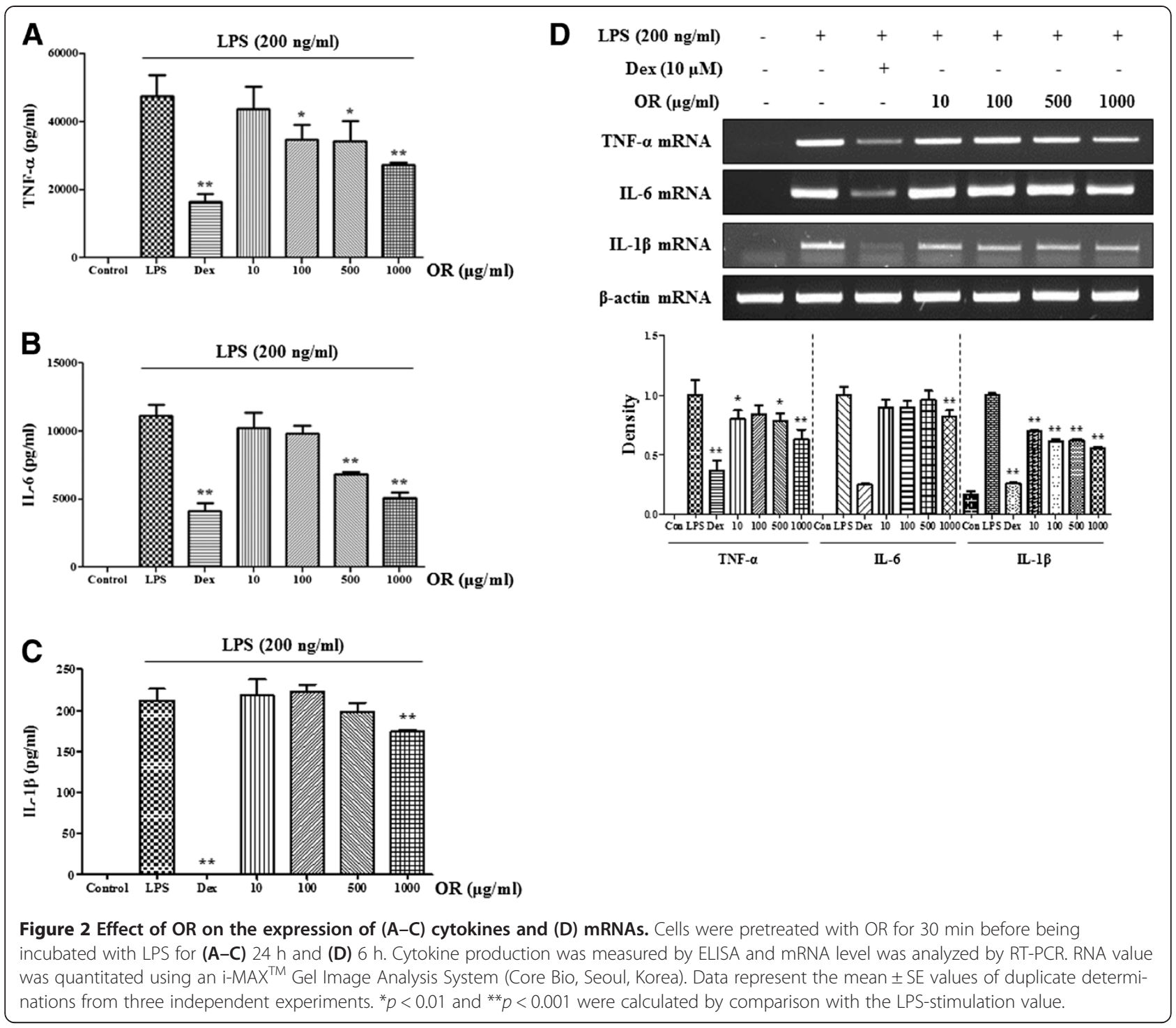

revealed changes in HO-1 induction upon OR treatment. First, we measured the expression of $\mathrm{HO}-13,6,12$, and $24 \mathrm{~h}$ after $1000 \mu \mathrm{g} / \mathrm{mL}$ OR treatment. HO-1 protein and mRNA expression were highest at 6 and $3 \mathrm{~h}$, respectively (Figure 3C). As shown in Figure 3D, OR induced HO-1 protein and mRNA expression at concentrations of 500 and $1000 \mu \mathrm{g} / \mathrm{mL}$ in a concentration-dependent manner.

\section{OR inhibits NF-KB pathway activation in macrophages upon LPS stimulation}

The NF- $\mathrm{KB}$ pathway is closely related to the production of inflammatory cytokines and iNOS. We examined the effects of OR on NF-kB activation by analyzing p65 translocation into the nucleus and the phosphorylation of IкB $\alpha$ in the cytosol. Western blot analysis revealed that $100-1000 \mu \mathrm{g} / \mathrm{mL}$ OR significantly repressed p65 translocation into the nucleus (Figure 4A). Also, as presented in Figure 4B, phosphorylation of ІкB $\alpha$ was suppressed in a concentration-dependent manner. Less IкB $\alpha$ was consistently found in the presence of the same OR concentrations. These results suggest that OR effectively inhibits LPS-induced NF-kB pathway activation by

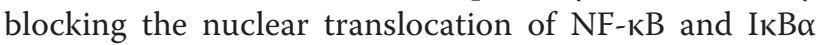
phosphorylation.

\section{OR suppresses LPS-induced phosphorylation of MAPKs in RAW 264.7 cells}

Because MAPKs activated by phosphorylation play an important role in NF- $\mathrm{kB}$ pathway activation, we examined the inhibitory effect of OR treatment on activation of the MAPK pathway. We examined the phosphorylation levels of MAPKs, including ERK 1/2, p38, and JNK. When RAW 264.7 cells were stimulated with LPS in the presence of OR, the level of phosphorylated ERK MAPK was significantly 


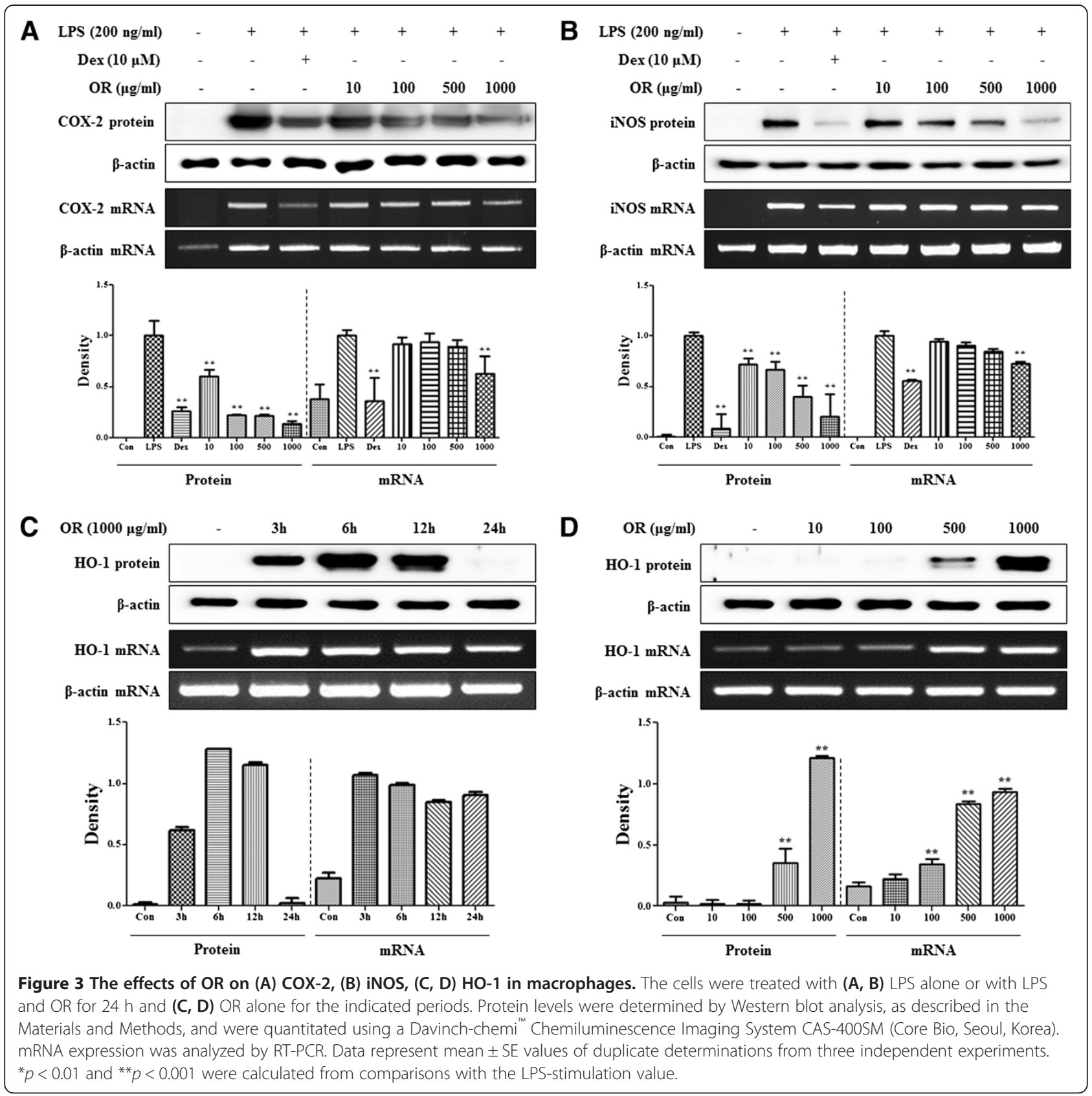

decreased (Figure 5A). However, OR $(1000 \mu \mathrm{g} / \mathrm{mL})$ did not affect p38 or JNK activity (Figure 5B and C). And, we determined that the total forms of ERK, p38, and JNK were not affected by OR treatment.

\section{Selection of suitable wavelengths}

To find the optimum absorbance for each analyte, we obtained UV/VIS spectra at a range of 190-400 $\mathrm{nm}$. The optimum absorbance for all analytes was determined to be $220 \mathrm{~nm}$ according to the individual absorbances: atractylenolid III, $227 \mathrm{~nm}$; cinnamic acid, $223 \mathrm{~nm}$; and cinnamaldehyde, $218 \mathrm{~nm}$ (Figure 6). The qualitative identification of three standards in OR was achieved using HPLC and was based on comparisons of UV wavelengths with those of the standard compounds.

Analysis of the contents using HPLC

The peaks of the three standards appeared at $26.96 \mathrm{~min}$ for cinnamic acid, $29.64 \mathrm{~min}$ for cinnamaldehyde and $35.55 \mathrm{~min}$ for atractylenolide III. Figure 7 shows that the standard compounds and mixture sample were separated successfully and analyzed simultaneously. Identification 


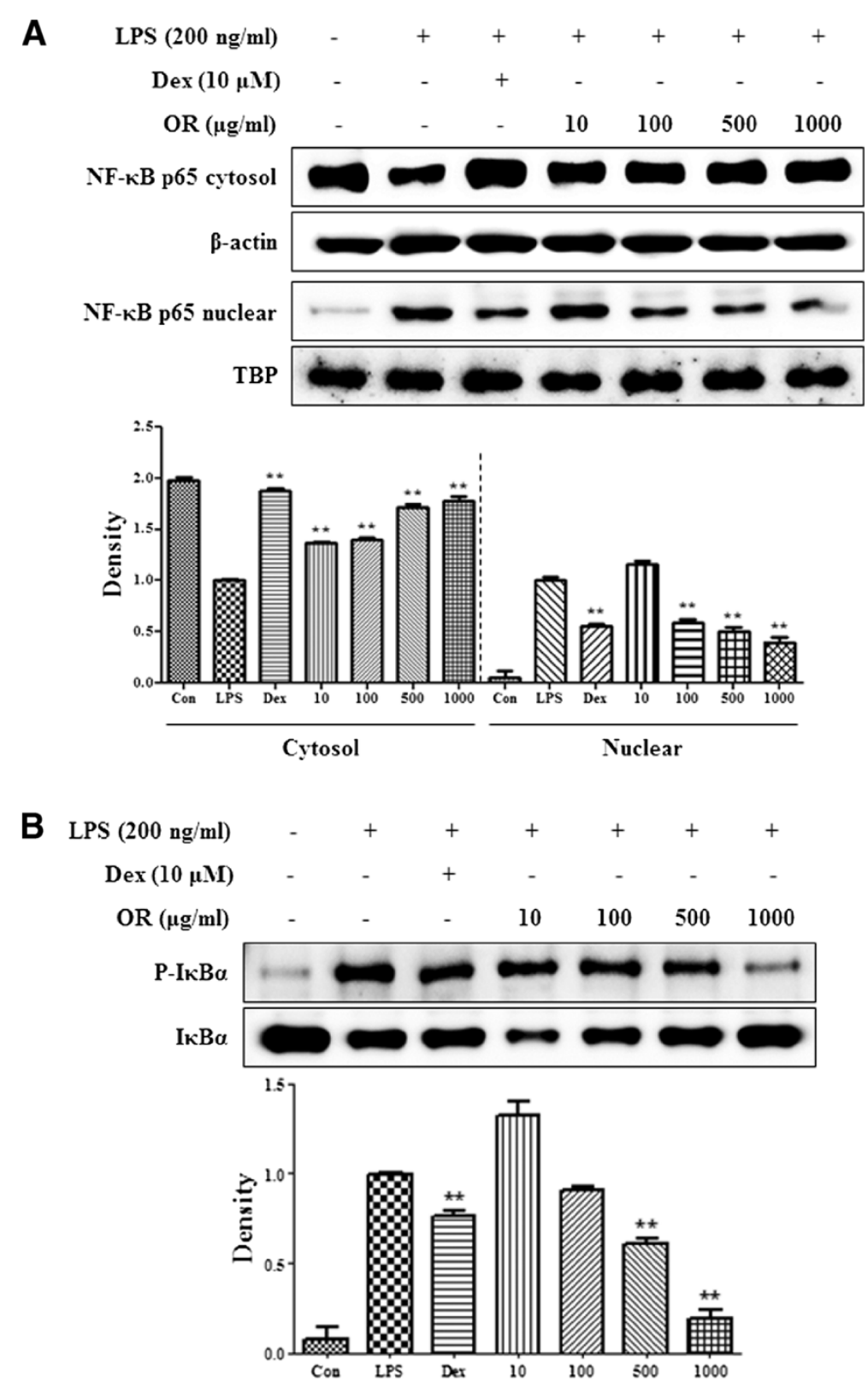

Figure 4 Inhibitory effect of OR on (A) NF-KB translocation into the nucleus and (B) IKBa phosphorylation. The cells were treated with LPS alone or with LPS and OR for $30 \mathrm{~min}(\mathrm{IKBa})$ or for $1 \mathrm{~h}(\mathrm{NF}-\mathrm{KB})$. Protein expression in the cytosol or nucleus was determined by Western blot analysis. Data represent mean \pm SE values of duplicate determinations from three independent experiments. ${ }^{*} p<0.01$ and ${ }^{* *} p<0.001$ were calculated from comparisons the with LPS-stimulation value.

of the certified OR compounds was based on comparisons of their retention times $\left(t_{R}\right)$ and chromatograms with those of the standard compounds (Figure 7).

\section{Discussion}

Previous studies on natural herbs and herbal decoctions using in vitro and in vivo systems have been conducted to discover potential anti-inflammatory products. OR is an important formulation in oriental traditional medicine, and has been commonly used to treat symptoms associated with renal diseases in East Asia since ancient times. OR has protective effects against acute gastric mucosal injury and an inhibitory effect on the renin-angiotensinaldosterone pathway $[1,2]$. Among the five herbs that making up OR, the anti-inflammatory effects of Atractylodes Rhizome White have been studied in RAW 264.7 cells [32]. The anti-inflammatory effects of cinnamon bark and Alisma rhizome have been studied in both in vitro 


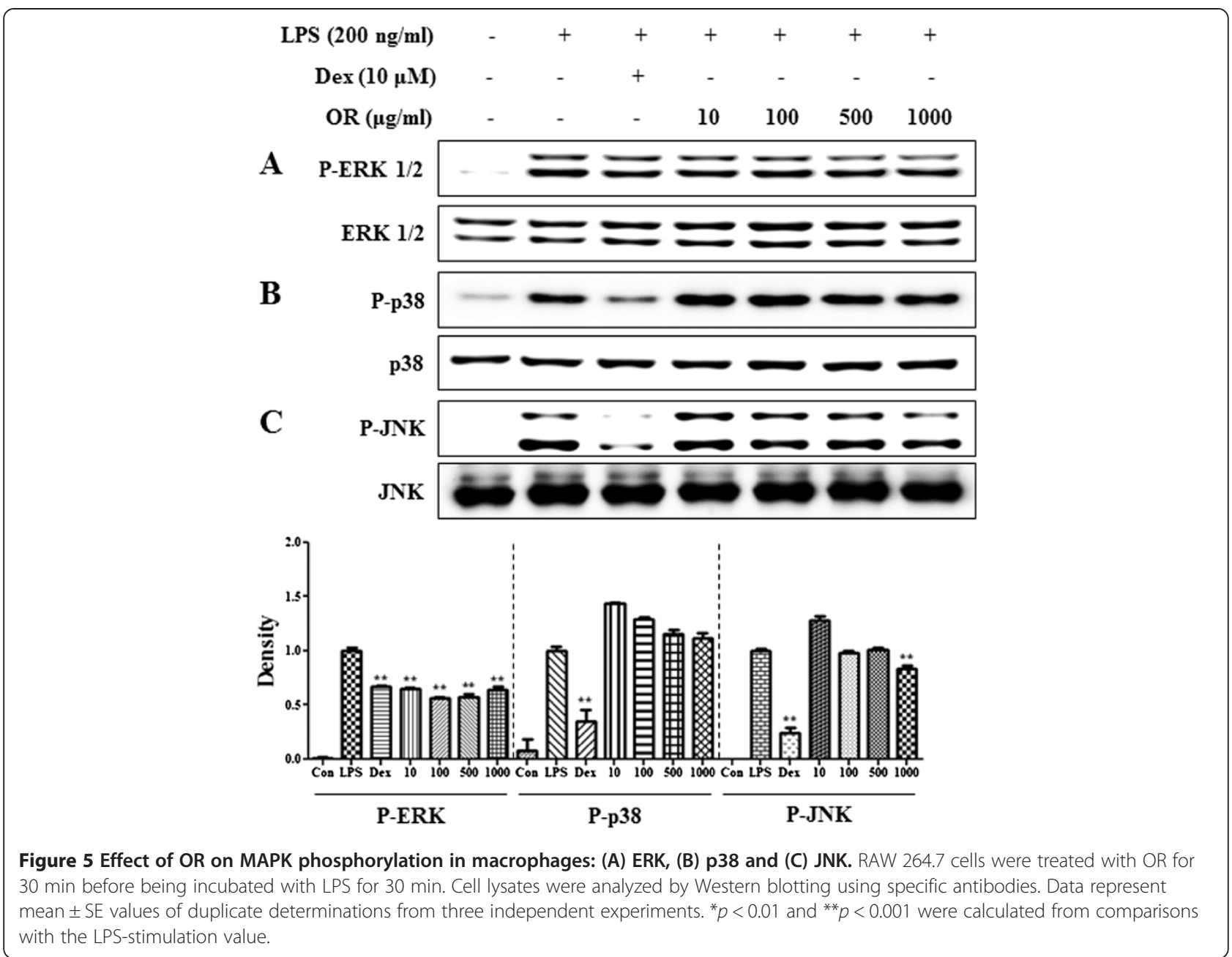

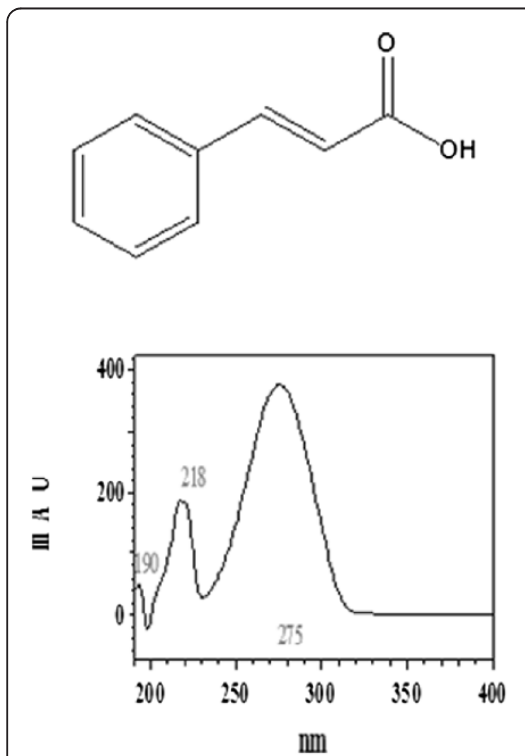

Cinnamic acid
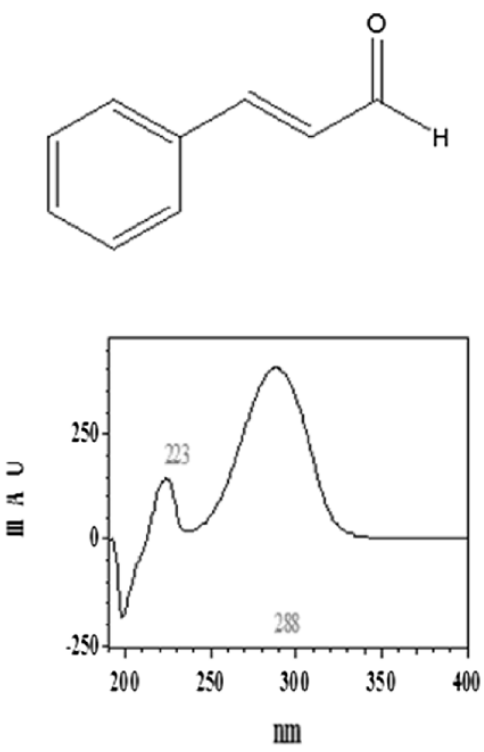

Cinnamaldehyde
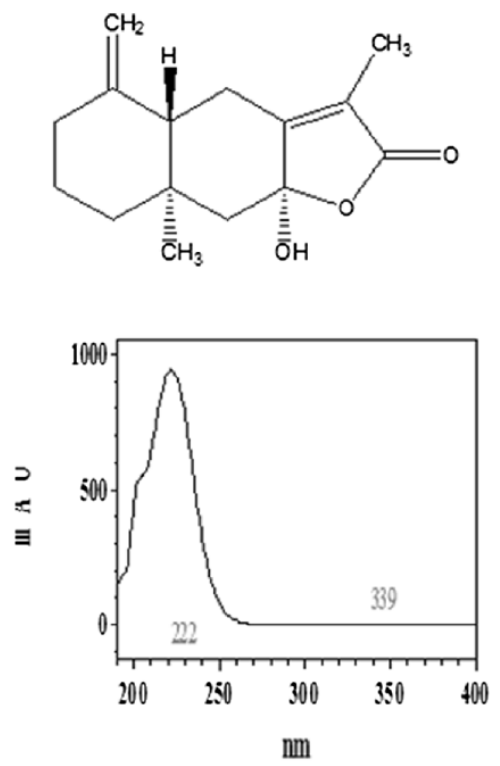

Atractylenolide III

Figure 6 Chemical structures and HPLC DAD spectra of the main constituents of OR. 


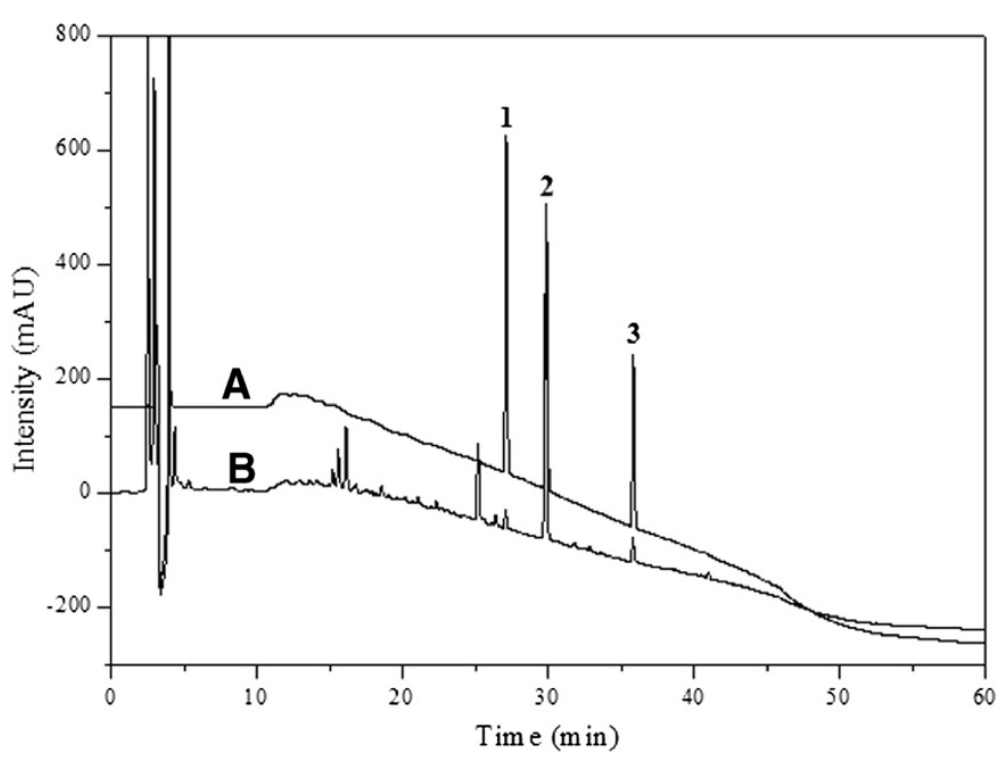

Figure 7 HPLC chromatograms of the (A) standard mixture and (B) OR at 220 nm. 1, Cinnamic acid, 26.96 min; 2, Cinnamaldehyde, $29.64 \mathrm{~min} ; 3$, Atractylenolide III, $35.55 \mathrm{~min}$.

and in vivo systems, and have been shown to have inhibitory effects on NF-kB activation [33,34].

In the present study, we demonstrated the antiinflammatory activity of OR in RAW 264.7 murine macrophages stimulated with LPS. First, we determined that OR treatment did not result in cytotoxicity of RAW 264.7 macrophages; it did not affect cell viability up to a concentration of $1000 \mu \mathrm{g} / \mathrm{mL}$. NO overproduction is associated with various inflammatory diseases [35,36], thus we investigated the inhibitory effects of OR on NO production induced by LPS stimulation. OR strongly suppressed NO secretion and inhibited iNOS expression and also suppressed COX-2 expression in a concentrationdependent manner. These results indicate that OR has inhibitory effects on the production of pro-inflammatory mediators.

The induction of HO-1 expression was due to a direct effect on iNOS expression [16]. Therefore, we investigated whether the inhibitory effect of OR on iNOS expression was associated with increased $\mathrm{HO}-1$ production. We found that OR pretreatment at a concentration of $500 \mu \mathrm{g} / \mathrm{mL}$ or greater induced HO-1 expression in RAW 264.7 macrophages, and also determined that it affected the inhibiting efficacy of NO and iNOS production. This finding suggests that inhibitory effect of OR on NO production was influenced by not only blockade on activation of NF-KB and MAPKs pathways but also induction of HO-1 expression.

OR concentration-dependently suppressed the inflammatory cytokines TNF- $\alpha$, IL- 6 and IL- $1 \beta$. NF- $\mathrm{kB}$ is a key transcriptional regulator associated with the cellular response to stimuli such as LPS [37-39]. Furthermore, it plays an important role in cell viability and the expression of various inflammatory factors including NO, inflammatory cytokines, and $\mathrm{PGE}_{2}$ [40-42]. To investigate whether the inhibitory effect of OR on the expression of cytokines and inflammatory factors is associated with NF- $\mathrm{kB}$ pathway activity, we measured the effect of OR on NF-kB nuclear transcription. We found that OR concentrationdependently inhibited the nuclear transcription of p65 through the inhibition of IкB $\alpha$ degradation by LPS stimulation. These findings are consistent with previous studies showing that the NF- $\mathrm{kB}$ response drives the expression of iNOS, TNF- $\alpha$, and IL- 6 genes [43-45]. Because of many anti-inflammatory drugs repress the production of inflammatory mediators through inhibition of NF- $\mathrm{kB}$ activity, OR extract could be developed as anti-inflammatory agents.

Because MAPKs activated by LPS are related to iNOS expression in macrophages [46], we also examined the inhibitory effect of OR on the phosphorylation of MAPKs. OR significantly inhibited phosphorylation of ERK MAPK, but had a little effect on the phosphorylation of p38 and JNK MAPK. These results indicate that the inhibitory effect of OR on the phosphorylation of MAPKs is directly related to inhibition of NF- $\kappa B$ activation and reduction of inflammatory factor production in RAW 264.7 cells. In this study, we investigated whether OR have inhibitory activity on various inflammatory mechanisms including NF-kB, MAPKs and HO-1. As a results, OR shows strongly biological effect on various signaling pathways. This experiment design in vitro inflammationrelated model was fundamental and comprehensive format in this field.

As shown in Figure 6, we identified three main components (cinnamic acid, cinnamaldehyde and atractylenolide 
III) in OR. A previous study reported that cinnamaldehyde has anti-inflammatory activities in vitro and in vivo [33]. Additionally, it was demonstrated that atractylenolide III inhibits LPS-induced TNF- $\alpha$ and NO production in macrophages [47]. These facts suggest that the anti-inflammatory activity of OR might be related to active components of OR, including cinnamaldehyde and atractylenolide III.

\section{Conclusions}

In conclusion, OR had a strong inhibitory effect on $\mathrm{NO}$ secretion, inflammatory cytokines production and expression of iNOS and COX-2 in LPS-stimulated RAW 264.7 cells. These effects were due to inhibition of NF- $\kappa B$

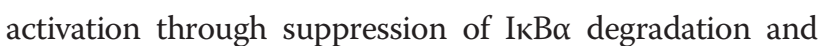
blockade of MAPK phosphorylation. Also, the influence of OR on HO-1 expression affected the suppression of inflammatory factors. These results suggest that OR could be developed as a new anti-inflammatory agent derived from natural products.

\section{Competing interests}

The authors declare that they have no competing interests.

\section{Authors' contributions}

YCO, YHJ, JHH, WKC and JYM participated in the design of the study, YCO carried out the experiments, analyzed the data and wrote the paper. All authors read and approved the final manuscript.

\section{Acknowledgements}

This work was supported by the grant K14050 awarded to Korea Institute of Oriental Medicine (KIOM) from Ministry of Education, Science and Technology (MEST), Korea.

Received: 3 April 2014 Accepted: 30 June 2014

Published: 14 July 2014

\section{References}

1. Jeon WY, Lee MY, Shin IS, Lim HS, Shin HK: Protective effects of the traditional herbal formula oryeongsan water extract on ethanol-induced acute gastric mucosal injury in rats. Evid Based Complement Alternat Med 2012, 2012:438191.

2. Ahn YM, Cho KW, Kang DG, Lee HS: Oryeongsan (Wulingsan), a traditional Chinese herbal medicine, induces natriuresis and diuresis along with an inhibition of the renin-angiotensin-aldosterone system in rats. J Ethnopharmacol 2012, 141:780-785.

3. Liu IM, Tzeng TF, Liou SS, Chang CJ: The amelioration of streptozotocin diabetes-induced renal damage by Wu-Ling-San (Hoelen Five Herb Formula), a traditional Chinese prescription. J Ethnopharmacol 2009, 124:211-218.

4. He L, Rong X, Jiang JM, Liu PQ, Li Y: Amelioration of anti-cancer agent adriamycin-induced nephrotic syndrome in rats by Wulingsan (Gorei-San) a blended traditional Chinese herbal medicine. Food Chem Toxicol 2008, 46:1452-1460.

5. Becker S, Mundandhara S, Devlin RB, Madden M: Regulation of cytokine production in human alveolar macrophages and airway epithelial cells in response to ambient air pollution particles: further mechanistic studies. Toxicol Appl Pharmacol 2005, 1:269-275.

6. Pierce GF: Macrophages: important physiologic and pathologic sources of polypeptide growth factors. Am J Respir Cell Mol Biol 1990, 2:233-234.

7. Guslandi M: Nitric oxide and inflammatory bowel diseases. Eur J Clin Invest 1998, 28:904-907.

8. Simons RK, Junger WG, Loomis WH, Hoyt DB: Acute lung injury in endotoxemic rats is associated with sustained circulating IL-6 levels and intrapulmonary CINC activity and neutrophil recruitment-role of circulating TNF-alpha and IL-beta? Shock 1996, 6:39-45
9. Wadleigh DJ, Reddy ST, Kopp E, Ghosh S, Herschman HR: Transcriptional activation of the cyclooxygenase- 2 gene in endotoxin-treated RAW 264.7 macrophages. J Biol Chem 2000, 275:6259-6266.

10. Kim JB, Han AR, Park EY, Kim JY, Cho W, Lee J, Seo EK, Lee KT: Inhibition of LPS-induced iNOS, COX-2 and cytokines expression by poncirin through the NF-kappaB inactivation in RAW 264.7 macrophage cells. Biol Pharm Bull 2007, 30:2345-2351.

11. Pae HO, Chung HT: Heme oxygenase-1: its therapeutic roles in inflammatory diseases. Immune Netw 2009, 9:12-19.

12. Terry CM, Clikeman JA, Hoidal JR, Callahan KS: Effect of tumor necrosis factor-alpha and interleukin-1 alpha on heme oxygenase-1 expression in human endothelial cells. Am J Physiol 1998, 274:883-891.

13. Srisook K, Cha YN: Super-induction of HO-1 in macrophages stimulated with lipopolysaccharide by prior depletion of glutathione decreases iNOS expression and NO production. Nitric Oxide 2005, 12:70-79.

14. Kaur H, Hughes MN, Green CJ, Naughton P, Foresti R, Motterlini R: Interaction of bilirubin and biliverdin with reactive nitrogen species. FEBS Lett 2003, 543:113-119.

15. Wang WW, Smith DL, Zucker SD: Bilirubin inhibits iNOS expression and NO production in response to endotoxin in rats. Hepatology 2004, 40:424-433.

16. Ashino T, Yamanaka R, Yamamoto M, Shimokawa H, Sekikawa K, Iwakura Y, Shioda S, Numazawa S, Yoshida T: Negative feedback regulation of lipopolysaccharide-induced inducible nitric oxide synthase gene expression by heme oxygenase-1 induction in macrophages. Mol Immunol 2008, 45:2106-2115

17. Kang SR, Han DY, Park KI, Park HS, Cho YB, Lee HJ, Lee WS, Ryu CH, Ha YL, Lee Do H, Kim JA, Kim GS: Suppressive effect on lipopolysaccharide-induced proinflammatory mediators by citrus aurantium L. In macrophage RAW 264.7 cells via NF-kB signal pathway. Evid Based Complement Alternat Med 2011, 2011:248592

18. Makarov SS: NF-KB as a therapeutic target in chronic inflammation recent advances. Mol Med Today 2000, 6:441-448.

19. de Martin R, Vanhove $B$, Cheng Q, Hofer E, Csizmadia V, Winkler H, Bach FH: Cytokine-inducible expression in endothelial cells of an IKBa-like gene is regulated by NF-KB. EMBO J 1993, 12:2773-2779.

20. Pahl HL: Activators and target genes of Rel/NF-kappaB transcription factors. Oncogene 1999, 18:6853-6866.

21. Baeuerle PA, Baltimore D: NF-kappa B: ten years after. Cell 1996, 87:13-20.

22. Wu LC, Fan NC, Lin MH, Chu IR, Huang SJ, Hu CY, Han SY: Antiinflammatory effect of spilanthol from Spilanthes acmella on murine macrophage by down-regulating LPS-induced inflammatory mediators. J Agric Food Chem 2008, 56:2341-2349.

23. Gilroy DW, Lawrence T, Perretti M, Rossi AG: Inflammatory resolution: new opportunities for drug discovery. Nat Rev Drug Discov 2004, 3:401-416.

24. Robinson MJ, Cobb MH: Mitogen-activated protein kinase pathways. Curr Opin Cell Biol 1997, 9:180-186.

25. Wang X, Martindale JL, Liu Y, Holbrook NJ: The cellular response to oxidative stress: influences of mitogen-activated protein kinase signalling pathways on cell survival. Biochem J 1998, 333(Pt 2):291-300.

26. Kim YH, Lee SH, Lee JY, Choi SW, Park JW, Kwon TK: Triptolide inhibits murine inducible nitric oxide synthase expression by down-regulating lipopolysaccharide-induced activity of nuclear factor-kappa B and c-Jun NH2-terminal kinase. Eur J Pharmacol 2004, 494:1-9.

27. Choi HJ, Kang OH, Park PS, Chae HS, Oh YC, Lee YS, Choi JG, Lee GH, Kweon $\mathrm{OH}$, Kwon DY: Mume Fructus water extract inhibits proinflammatory mediators in lipopolysaccharide-stimulated macrophages. J Med Food 2007, 10:460-466.

28. Jo HY, Kim Y, Nam SY, Lee BJ, Kim YB, Yun YW, Ahn B: The inhibitory effect of quercitrin gallate on iNOS expression induced by lipopolysaccharide in Balb/c mice. J Vet Sci 2008, 9:267-272.

29. Kim HY, Kim JK, Choi JH, Jung JY, Oh WY, Kim DC, Lee HS, Kim YS, Kang SS, Lee SH, Lee SM: Hepatoprotective effect of pinoresinol on carbon tetrachlorideinduced hepatic damage in mice. J Pharmaco/ Sci 2010, 112:105-112.

30. Srisook K, Palachot M, Mongkol N, Srisook E, Sarapusit S: Anti-inflammatory effect of ethyl acetate extract from Cissus quadrangularis Linn may be involved with induction of heme oxygenase- 1 and suppression of NF-KB activation. J Ethnopharmacol 2011, 133:1008-1014.

31. Kwon DJ, Ju SM, Youn GS, Choi SY, Park J: Suppression of iNOS and COX-2 expression by flavokawain A via blockade of NF-KB and AP-1 activation in RAW 264.7 macrophages. Food Chem Toxicol 2013, 58:479-486. 
32. Jang MH, Shin MC, Kim YJ, Kim CJ, Kim Y, Kim EH: Atractylodes japonica suppresses lipopolysaccharide-stimulated expressions of inducible nitric oxide synthase and cyclooxygenase-2 in RAW 264.7 macrophages. Biol Pharm Bull 2004, 27:324-327.

33. Liao JC, Deng JS, Chiu CS, Hou WC, Huang SS, Shie PH, Huang GJ: Antiinflammatory activities of cinnamomum cassia constituents in vitro and in vivo. Evid Based Complement Alternat Med 2012, 2012:429320.

34. Han CW, Kwun MJ, Kim KH, Choi JY, Oh SR, Ahn KS, Lee JH, Joo M: Ethanol extract of Alismatis Rhizoma reduces acute lung inflammation by suppressing NF-KB and activating Nrf2. J Ethnopharmacol 2013, 146:402-410.

35. Guzik TJ, Korbut R, Adamek-Guzik T: Nitric oxide and superoxide in inflammation and immune regulation. J Physiol Pharmacol 2003, 54:469-487.

36. Southan GJ, Szabo C: Selective pharmacological inhibition of distinct nitric oxide synthase isoforms. Biochem Pharmacol 1996, 51:383-394.

37. Brasier AR: The NF-kappaB regulatory network. Cardiovasc Toxicol 2006, 6:111-130.

38. Gilmore TD: Multiple mutations contribute to the oncogenicity of the retroviral oncoprotein v-Rel. Oncogene 1999, 18:6842-6844.

39. Tian B, Brasier AR: Identification of a nuclear factor kappa B-dependent gene network. Recent Pro Hor Res 2003, 58:95-130.

40. Chen F, Kuhn DC, Sun SC, Gaydos LJ, Demers LM: Dependence and reversal of nitric oxide production on NF-kappa B in silica and lipopolysaccharide-induced macrophages. Biochem Biophys Res Commun 1995, 214:839-846.

41. Roshak AK, Jackson JR, McGough K, Chabot-Fletcher M, Mochan E, Marshal LA: Manipulation of distinct NFkappaB proteins alters interleukin-1 betainduced human rheumatoid synovial fibroblast prostaglandin $E_{2}$ formation J Biol Chem 1996, 271:31496-31501.

42. Xie W, Merrill JR, Bradshaw WS, Simmons DL: Structural determination and promoter analysis of the chicken mitogen-inducible prostaglandin $\mathrm{G} / \mathrm{H}$ synthase gene and genetic mapping of the murine homolog. Arch Biochem Biophys 1993, 300:247-252.

43. Ahn KS, Noh EJ, Zhao HL, Jung SH, Kang SM, Kim YS: Inhibition of inducible nitric oxide synthase and cyclooxygenase II by Platycodon grandiflorum saponins via suppression of nuclear factor-kappaB activation in RAW 264.7 cells. Life Sci 2005, 76:2315-2328.

44. Barnes PJ, Karin M: Nuclear factor-kappaB. A pivotal transcription factor in chronic inflammatory diseases. N Engl I Med 1997, 336:1066-1071.

45. Kim YM, Lee BS, Yi KY, Paik SG: Upstream NF-kappaB site is required for the maximal expression of mouse inducible nitric oxide synthase gene in interferon-gamma plus lipopolysaccharideinduced RAW 264.7 macrophages. Biochem Biophys Res Commun 1997, 236:655-660.

46. Caivano M: Role of MAP kinase cascades in inducing arginine transporters and nitric oxide synthetase in RAW 264.7 macrophages. FEBS Lett 1999, 429:249-253.

47. Li CQ, He LC, Jin JQ: Atractylenolide I and atractylenolide III inhibit Lipopolysaccharide-induced TNF-alpha and NO production in macrophages. Phytother Res 2007, 21:347-353.

doi:10.1186/1472-6882-14-242

Cite this article as: Oh et al:: Oryeongsan inhibits LPS-induced production of inflammatory mediators via blockade of the NF-kappaB, MAPK pathways and leads to HO-1 induction in macrophage cells. BMC Complementary and Alternative Medicine 2014 14:242.

\section{Submit your next manuscript to BioMed Central and take full advantage of:}

- Convenient online submission

- Thorough peer review

- No space constraints or color figure charges

- Immediate publication on acceptance

- Inclusion in PubMed, CAS, Scopus and Google Scholar

- Research which is freely available for redistribution 